\title{
TRACHEOBRONCHIAL ASPIRATION SYNDROME
}

\section{SINDROM TRAHEOBRONHIJALNE ASPIRACIJE}

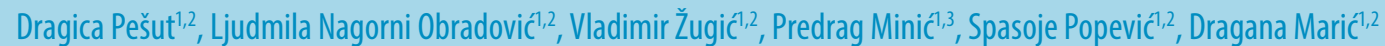

\section{Summary}

Aspiration-inhalation of solid or liquid materials into the airways-occurs when solids or liquids are introduced into the supraglottic area rapidly or in large volumes or when airway defences are reduced by structural abnormalities or neurological impairment. Tracheobronchial aspiration (TBA) syndrome is currently among leading causes of morbidity and mortality in the world when it comes to accidents, and it is the leading cause in oneyear-old children. During the last several years, destructive effects of some food and drugs on respiratory system have been revealed. TBA may cause no complications at all or may result in a range of complications from paroxysmal cough to respiratory failure and lethal outcome. Rapid diagnosis is of utmost importance in correct interventions that should be done in a timely manner, and in prevention of complications, which are sometimes irreversible. This is a review of TBA syndrome etiopathogenesis with special reference to those caused by solid foreign bodies, including those of biological origin, hydrocarbons, lipids, and water - drowning. Special attention is given to TBA syndrome in children, and to complications such as aspiration pneumonia and pneumonitis. Current approach in treatment of the syndrome is explained in dependence of its etiology. Importance, indications and possibilities of interventional bronchoscopy are highlighted.

Keywords: Aspiration, tracheobronchial; foreign body, pneumonia; pneumonitis; bronchoscopy, interventional; criotherapy

\section{Sažetak}

Aspiracija - unošenje čvrstog ili tečnog sadržaja različith (bio)hemijskih svojstava u disajne puteve udisanjem - događa se kad se čvrsto telo ili tečnost unesu u supraglotičnu regiju ili velike disajne puteve brzo ili u većoj koliličini ili u slučaju da je odbrana disajnih puteva smanjena strukturnim poremećajima ili/i neurološkim oštećenjem. Danas je sindrom traheobronhijalne aspiracije (TBA) među vodećim uzrocima morbiditeta i mortaliteta u svetu u odnosu na sve ostale zadesne slučajeve a vodeći kod dece u prvoj godini života. Poslednjih godina su rasvetljeni razorni efektni nekih životnih namirnica i lekova na respiratorni sistem. TBA ne mora da izazove ikakve komplikacija a može da dovede do čitavog spektra patoloških stanja, od paroksizmalnog kašlja do respiratorne insuficijencije i letalnog ishoda. Brza dijagnoza je od ključnog značaja u korektnom, pravovremenom zbrinjavanju i sprečavanju komplilkacija od kojih su neke ireverzibilne. U radu je dat pregled etiopagoneze sindroma TBA sa posebnom osvrtom na one izazvane aspiracijom čvrstih stranih tela, uključujući ona biljnog i životinjskog porekla, ugljovodonika, lipida i vode - utopljenja. Poseban osvrt je dat na TBA kod dece kao i na komplikacije kao što su aspiraciona pneumonija i pneumonitis. Izneseni su savremeni vidovi zbrinjavanja ovih bolesnika zavisno od etiologije sindroma. Naglašen je značaj, indikacije i mogućnosti interventne bronhoskopije u dijagnostičko-terapijskom pristupu.

Ključne reči: Aspiracija, traheobronhijalna; strano telo; pneumonija; pneumonitis; bronhoskopija, interventna; krioterapija.

\section{UvoD}

Aspiracija-unošenje čvrstog ili tečnog sadržaja različitih (bio)hemijskih svojstava u disajne puteve udisanjem-aspiracija-događa se kad se čvrsto telo ili tečnost brzo unesu u supraglotičnu regiju ili velike disajne puteve ili kad je odbrana disajnih puteva smanjena strukturnim poremećajima ili/i neurološkim oštećenjem (1-5).

Sindrom traheobronhijalne aspiracije (TBA) je danas među vodećim uzrocima morbiditeta i mortaliteta $u$ svetu u odnosu na sve ostale zadesne slučajeve, a vodeći kod dece u prvoj godini života $(2,5)$. Većina od oko $80 \%$ prepoznatih slučajeva bila je kod mlađih od 15 godina. Brojne retrospektivne studije su pokazale da je ova učestalost u pedijatrijskoj praksi najveća kod mlađih od tri godine, posebno kod dečaka (2).

\section{ETIOLOGIJA I PATOGENEZA ASPIRACIJE STRANOG SADRŽAJA U DISAJNE PUTEVE}

Sindrom TBA je najčešće izazvan aspiracijom neorganskog ili organskog stranog tela, uključujući i ona biljnog i životinjskogporekla, orofaringealnog ili gastičnog sadržaja, ugljovodonika, lipida i vode $(1,2,6)$. Kad strano telo dospe u distalni deo bronhijalnog sistema a ne izazove akutnu opstrukciju, posledice ovakve aspiracije variraju u zavisnosti od prirode aspiriranog materijala. Zavisno od sastava aspiriranog sadržaja, sindrom TBA može da se javi pod slikom aspiracione pneumonije i pneumonitisa, lipoidne pneumonije, odnosno, utopljenja vodom (1).

Poslednjih godina su rasvetljeni i ranije malo poznati razorni efekti sastojaka pojedinih aspiriranih životnih namirnica i lekova na respiratorni sistem $(7,8)$. Lekovi u vidu tableta i pilula čine $7 \%$ svih aspiriranih stranih tela sa raznolikim posledicama u vidu opstrukcije, sistemskih i lokalnih efekata (9). Dijagnoza se postavlja 
Tabela 1. Najčěčce komplikacije traheobronhijalne aspiracije

AKUTNE
- Hemoptizije
- Asfiksija
- Pdem larinksa
- Pneumotoraks
- Ruptura traheje/bronha
- Cardiac arrestx

\section{KASNIJE ILI HRONIČNE}

- Postoopstrukcijski emfizem

- Atelektaza

- Striktura bronha

- Pneumonija

- Uporni kašalj

- Uporne hemoptizije

- Lokalizovane bronhiektazije

- Hronična postopstruktivna pneumonija

- Apsces pluća

- Bronho-pleuralna fistula

- Traheo-ezofagusna fistula

- Medijastinitis na osnovu anamneze sa tačnim podatkom o vremenu uzimanja i vrsti leka, često uz normalan radiogram grdunog koša i u odsustvu stranog tela prilikom bronhoskopije. Organski materijali mogu da izazovu tešku lokalizovanu inflamaciju sluzokože, a granulaciono tkivo da se razvije već za nekoliko sati $(5,9)$.

Predmeti koji apsorbuju vodu, kao što su zrno pasulja, kukuruza i razne semenke, mogu da nabubre i od parcijalne opstrukcije dovedu do totalne. Tako, kod osoba koje su inhalirale male organske predmete, simptomi mogu potpuno da izostanu sve dok se ne desi totalna opstrukcija. Neki delovi biljaka kao što je popino prase mogu da migriraju distalno i dovedu do hronične inflamacije koja zahteva resekciju pluća. Semenke lubenice su bile najčešća aspirirana strana tela (66\%) u velikoj desetogodišnjoj studiji Univerzitetske dečje klinike u Bagdadu a kiki riki u američkoj studiji u Memfisu (10, 11). Dvadesetogodišnja jordanska studija je našla da su u jednoj trećini slučajeva strana tela semenke, najviše od lubenice, orasi i orašasti plodovi pa biljke u jednoj četvrtini slučajeva (12). Prema istraživanju Klinike za otorinolaringologiju u Tuzli, tokom 50-godišnjeg perioda, u $87 \%$ slučajeva aspirirana strana tela kod dece od osam meseci do 14 godina bila su organskog porekla (13).

Poseban problem predstvljaju živa strana tela u bronhijalnom stablu $(14,15)$. Opisi aspiracije ribe datiraju iz 16.veka. Do nje dolazi usled navike ribara da ulov stave u usta. Pri naglom pregrizanju, riba lako sklizne u bronhijalno stablo, odakle se teško u komadićima eliminiše zbog brzo nastalog raspadanja. U savremenoj literaturi su opisi aspiracije živog stranog tela retki. Novi prikaz živih tela u bronhijalnom stablu baziran na literaturi objavljenoj na više jezika (engleski, latinski, španski, ruski, francuski, nemački, slovački i kineski) ukazuje da su to najčešće ribe, pijavice (Hirudo medicinalis) i crvi (Ascaris) (14)

Najčešći faktori rizika i stanja predispozicije za TBA su hronične teške bolesti, medicinske i stomatološke intervencije u orofaringealnoj i laringotrahealnoj zoni, izmenjeno psihičko stanje i poremećaj gutanja $(1,6,16)$. Više ovih faktora može da bude prisutno istovremeno kod starih osoba.
Kako se najveći broj TBA događa bez prisustva svedoka, pravovremena dijagnoza se zasniva na visokom stepenu sumnje. Klinička slika i radiografski nalaz mogu veoma da variraju a zavise od prirode i količine aspirirarnog sadržaja ili aspiriranog predmeta. Aspiracija stranog tela ili relativno velika količina aspiriranog materijala može da izazove akutnu ili subakutnu sliku koja se kreće od zagrcnjavanja, akutne pneumonije, ugušenja zalogajem hrane i iznenadne smrti (17). Ponavljana aspiracija male količine želudačne kiseline može postupno da dovede do rekurentne pneumonije, bronhiektazija ili plućne fibroze. Vreme od aspiracije stranog tela do pojave tegoba varira. Simptomi, najčešće u vidu kašlja, mogu da se ispolje u prva 24 sata ili posle šest meseci od aspiracije (18).

Komplikacije TBA mogu da budu akutne ili hronične, odnosno, da se jave kasnije iza različito dugog perioda iza aspiracije (Tabela 1), $(1,16,17)$. Sindrom TBA spada u ona stanja koja zahtevaju hitno prepoznavanje i lečenje, kako bi se ove komplikacije svele na minimum.

\section{Aspiraciona PNEUMoniJa I PNEUMONITIS}

Aspiraciona pneumonija je zapaljenski proces na plućima nastao posle aspiracije orofaringealnog ili egzogenog sadržaja u traheobronhijalno stablo. Procenjuje se da čini oko $15 \%$ obolelih sa pneumonijom ali ova učestalost je veća kod poremećaja stanja svesti (cerebrovaskularni insult, alkoholizam, stanje posle opšte anestezije, trovanje lekovima i dr.), neuroloških oboljenja (parkinsonizam, miastenia gravis, epilepsija i dr.), disfagije, mehaničkog ometanja funkcije glotisa i ezofagealnih sfinktera (traheostoma, ishrana putem nazogastrične sonde, bronhoskopija) kao i starijih osoba sa hroničnim udruženim bolestim (16). Aspiraciona pneumonija predstavlja uzrok smrti u skoro $20 \%$ osoba u staračkim domovima (19). Komplikacije mogu da se jave u vidu apscesa pluća, empijema pleure i bronhopleuralne fistule.

Aspiracioni pneumonitis nastaje aspiracijom sadržaja sa hemijskim dejstvom kao što su želudačni sadržaj, 
ulja (mineralna ulja, petrolej, parafin, sredstava protiv opstipacije), lipidi (masnoće iz hrane). Može da dovede do teških hemijskih oštećenja traheobronhijalnog stabla. Prognoza bolesti zavisi od količine aspiriranog sadržaja. Akutni respiratorni distres sindrom (ARDS) nastaje kao teška komplikacijakoja u više od 50\% dovodi do smrtnogishoda $(20,21)$. Veoma je važno da se posebna pažnja usmeri na preventivne mere nastanka ovih patoloških stanja, a posebno kod osoba sa navedenim visokim rizikom.

\section{LIPOIDNA PNEUMONIJA I PNEUMONITIS}

Aspiracijom masnih supstanci nastaje egzogena lipoidna pneumonija, dok aspiracija ugljovodonika dovodi do akutnog hemijskog pnemonitisa, koji je vrlo sličan lipoidnoj pneumoniji. Akutna egzogena lipoidna pneumonija obično je povezana sa određenim zanimanjima ili načinom ponašanja („gutači vatre“, osobe koje izvlače dizel gorivo iz rezervoara), dok je hronična posledica dugotrajnog korišćenja supstanci koje sadrže masnoće (laksativi, sjaj za usne, balzam za usne i drugo) (22-24).

Početak bolesti najčešće je neprimetan, a klinička slika nespecifična, pri čemu u simptomatologiji dominiraju kašalj i dispneja. Radiografske manifestacije su, takođe, potpuno nespecifične, tako da se nalazi kompjuterizovane tomografije grudnog koša kreću od parenhimskih infiltrata u plućima, perifernih nodula i zasenčenja po tipu mlečnog stakla, često kombinovanih sa zadebljanjem interlobarnih septi i trakastim intralobularnim zadebljanjima (eng. crazy-paving)(25). Ovakve radiografske manifestacije predstavljaju diferencijalno-dijagnostički problem, prvenstveno zbog sličnosti sa drugim bolestima pluća (pneumonija, karcinom, fibroza).

Za postavljanje dijagnoze najvažnija je dobro uzeta anamneza, posebno njen deo o izloženosti faktorima rizika. Definitivna dijagnoza se postavlja nalazom makrofaga ispunjenih mastima u sputumu, bronhoalveoolarnom lavatu ili uzorku biopsije plućnog parenhima (1). Tok bolesti je u najvećem broju slučajeva povoljan sa retkim komplikacijama.

\section{ASPIR ACIJA VODE - UTOPLJENJE}

Pod utopljenjem se podrazumevaju dva stanja: smrt zbog asfiksije posle potapanja u tečnostima (treći najčešći uzrok zadesne smrti u svetu) ali i stanje neposrednog preživljavanja asfiksije posle potapanja u tečnostima, sa svim eventualnim komplikacijama. Patofiziološki mehanizmi ove aspiracije nisu sasvim jasni, ali se smatra $\mathrm{da}$, posle inicijalnog laringospazma, dolazi do relaksacije muskulature i prodora vode u donje disajne puteve, što je često praćeno, uz efekte dodatnih faktora (hladnoća), srčanim zastojem $(1,26-28)$.
Kod preživelih osoba, česte su komplikacije (hipoksijska encefalopatija, aspiraciona pneumonija, ARDS i drugo), čiji nastanak, tok i ishod zavise od trajanja i uslova potapanja, u koje spada i specifična težina vode $(1,28)$. Respiratorna insuficijencija je najznačajnija posledica kod preživelih utopljenika. Pa ipak, povrede drugih delova tela, posebno glave i cervikalne kičme, mogu da se očekuju i zahtevaju procenu stanja. Utopljenici mogu da se oporave bez ikakvih sekvela uz uslov da nije došlo do ireverzibilnog oštećenja usled moždane hipoksije.

\section{ASPIRACIONI SINDROM KOD DECE}

Aspiracija stranog sadržaja u disajne puteve je relativno česta pojava čija ispoljavanja mogu da se kreću u spektru od potpuno neprimetnih, minimalnih respiratornih smetnji, pa do masivnih koje dovode do respiratorne insuficijencije i smrti. Deca mogu da aspiriraju različite sadržaje: u uzrastu novorođenčeta-mekonijumom kontaminiranu plodovu vodu, kasnije, u uzrastu do tri godine, sitne delove koštunjavih plodova, toksične tečnosti (organske rastvarače, insekticide), sekret iz nosa i usta, gastrički sadržaj i egzogeno kontaminirani materijal $(2,4,5,11-13)$.

Aspiracija klinički može da se ispolji znacima i simptomima opstrukcije velikih disajnih puteva (atelektaza, asfiksija, hiperinflacija, sviranje u grudima, stridor i apneja), akutnog hemijskog oštećenja (difuzni infiltrati, akutni respiratorni distres sindrom), infekcije (pneumonija, apsces pluća i empijem pleure) ili recidivnog hemijskog oštećenja (bronhitis, bronhiolitis, pneumonija, atelektaza, sviranje u grudima, hronični kašalj, apneja, laringospazam i gastroezofagusni refluks /GER/) $(2,29)$.

Stanja i poremećaji koji su udruženi sa aspiracionim sindromima mogu da se podele na strukturne (mikrognacija, makroglosija, rascep nepca, rascep larinksa i traheje, traheoezofagusna fistula, vaskulni prstenovi, GER, traheostoma i nazogastrička sonda), neuromišićne (izmenjena svest, poremećaj akta gutanja, cerebralna paraliza, povišen intrakranijalni pritisak, paraliza glasnica, mišićna distrofija, mijastenija gravis, GuillainBarré sindrom, spinalna mišićna atrofija tip I) i ostale (trauma, opstrukcijska apneja u spavanju) (29).

Aspiracija stranog tela (AST) je važan uzrok morbiditeta i mortaliteta kod dece, za koji se vezuje 5\% smrtnih ishoda kod dece mlađe od četiri godine. U zemljama bez razvijene politike prevencije, ovi pokazatelji su još lošiji $(2,5,29)$. Aspiracija stranog tela je češća kod dečaka zbog nivoa aktivnosti i kod dece mlađe od tri godine zbog nerazvijenosti molara i neadekvatnog žvakanja.

Dijagnoza aspiracionog sindroma kod dece može da bude teška zbog toga što nedostaju dovoljno specifične analize kojima bi se uspostavila veza između aspiraci- 
je i kliničkog ispoljavanja plućne bolesti. GER je često udružen sa respiratornim poremećajima, ali je aspiracija samo jedan od mogućih objašnjenja ove udruženosti. Gutanje je veoma složena funkcija i njegov poremećaj se smatra važnim uzrokom recidivnih pneumonija kod dece. I dijagnoza i lečenje recidivnih aspiracija treba da budu individualizovani za svakog bolesnika.

Sumnja na AST kod dece se postavlja na osnovu naglo nastalog zagrcnjavanja, kašlja praćenog pojavom stridora, sviranja u grudima ili oslabljenog disanja. Za odluku o bronhoskopiji presudna se sumnja postavljena posle uzimanja anamneze, a ne radiološki ili klinički nalaz koji često nemaju dovoljnu dijagnostičku specifičnost i senzitivnost (30).

Potrebno je da se rano posumnja, brzo dijagnostikuje i potpuno ukloni strano telo. Zakašnjenje u vađenju stranog tela može da ima za posledicu teške bronhopulmonalne sekvele-recidivne pneumonije i bronhiektazije. $U$ iračkoj studiji je od 2710 dece kod kojih je u desetogodišnjem periodu postavljena sumnja na AST, to i dokazano u $84 \%$ slučajeva (10).

\section{TERAPIJSKI PRISTUP BOLESNIKU SA SINDROMOM TBA}

Lečenje varira i zavisi od etiologije sindroma TBA (primer: aspirirano strano telo, želudačni sadržaj ili ugljovodonik) i kliničke slike (primer: hipoksemija ili znaci infekcije). Kod aspiracione pneumonije i pneumonitisa sa ili bez drugih komplikacija, terapiju čine antibiotici koji pokrivaju anaerobnu floru. Oksigenoterapija se primenjuje u stanjima hipoksemije. Inhalirani sadržaj treba da se odstrani posturalnom drenažom ili bronoskopijom. Posebno kod dece, lečenje recidivnih aspiracija treba da bude individualizovano.

U slučaju lipoidne pneumonije, terapijski pristup nije određen. Kortkosteroidi se primenjuju samo u pojedinim slučajevima sa progresivnim oštećenjem pluća, dok se, takođe u pojedinim slučajevima, primenjuju imunoglobulini ili bronhoalveolarna lavaža celih pluća. Ponavljana bronhoalveolarna lavaža se primenjuje i kod utopljenika iza aspiracije peska, gde radiografski pregled pomaže u dijagnozi. U slučaju potrebe, tokom bronhoalveolarne lavaže dodatno se primenjuje oksigenoterapija, koja može da bude izvedena i putem ekstrakorporalne membranske oksigenacije $(31,32)$.

Inicijalno lečenje utopljenika podrazumeva kardiopulmonalnu reanimaciju, parenteralnu nadoknadu tečnosti, intubaciju sa mehaničkom ventilacijom kod davljenika bez svesti, odnosno, primenu neinvazivne ventilacije kod svesnih osoba. Kod određenih davljenika primenjuje se terapijska hipotermija (33). Posebno hlađenje glave/mozga može da bude značajno u preven- ciji neuroloških komplikacija. Prema dosadašnjim saznanjima, profilaktička primena antibiotika i kortikosteroida se retko preporučuju.

U pristupu bolesniku sa sindromom TBA posebno mesto zauzimaju interventne bronhoskopske procedure. Bronhoskopija ima najznačajniju ulogu i u dijagnostici i u lečenju aspiracije stranog tela. Pre intervencije, prvo je potrebno da se bronhoskopski odredi anatomska lokalizacija, vrsta i sastav aspiriranog materijala, odnos sa okolnim strukturama, prisustvo edema, fistule $\mathrm{i} / \mathrm{ili}$ granulacija i na osnovu toga planira interventna proceduru, uz pažliivu procenu rizika. Koriste se i fleksibilna i rigidna bronhoskopija, nekada i kombinovano u istoj intervenciji. Rigidna bronhoskopija u opštoj anesteziji ima prednost u zbrinjavanju opstrukcije velikih disajnih puteva izazvane čvrstim ili polučvrstim stranim telima a fleksibilna u aspiraciji tečnog sadržaja ili za ekstrakciju stranih tela u segmentnim i subsegmentnim bronhima $(1,34)$.

Čvrsta strana tela koja ne sadrže vodu ekstrahuju se forcepsom ili posebnim instrumentima kao što je „korpica" (eng, basket) a ako sadrže vodu, metoda izbora je krioekstrakcija (primena kriosonde sa tečnim azotom ili ugljen dioksidom, kojom se strano telo zamrzava i u celini uklanja) $(35,36)$. Ova metoda se često koristi za ekstrakciju koaguluma iz traheobronhijalnog stabla (37). Krioterapija granulacionog tkiva radi prevencije fibrostenoze bronha posle aspiracije je metoda koja se danas intenzivno ispituje (38). Krioekstrakcija se pokazala uspešnom i u ekstrakciji aspirirane žvakaće gume (39). Manje traheoezofagealne fistule mogu da se reše, izmedju ostalog, i postavljanjem trahealnog stenta. Poseban terapijski problem je atelektaza kod bolesnika u jedinicama intenzivne nege na mehaničkoj ventilaciji. Ako se ne sumnja na fistulu, aspiraciju stranog tela ili želudačnog sadržaja, terapijska bronhoskopija sa lavažom je u ovim slučajevima metoda drugog izbora i rezervisana je za bolesnike kod kojih nije postignut odgovor na intenzivnu fizikalnu terapiju.

Stanja iza aspiracije živih stranih tela zahtevaju dodatnu terapiju zavisno od nađenog uzročnika (antihelmintici itd) (15).

\section{ZAKLJUČAK}

Traheobronhijalna aspiracija je stanje koje ne mora klinički da se ispolji a može da izazove komplikacije sa širokim spektrom patoloških poremećaja, od kojih su neki ireverzibilni a neki ugrožavaju život. Brza dijagnoza je od ključnog značaja u korektnom, pravovremenom zbrinjavanju i sprečavanju komplikacija. Interventna bronhoskopija ima značjno mesto u terapijskom pristupu TBA, uključujući i metodu krioekstrakcije. U prevenciji aspiracije stranog tela kod dece nephodno je 
sprovođenje kontinuiranih programa edukacije, kao i označavanje pakovanja zrna koštunjavog voća sa upozorenjem da njihovo uzimanje može da bude opasno za decu mlađu od pet godina.
Rad je usmeno izložen na mini simpozijumu Sindrom traheobronhijalne aspiracije, na 45. simpozijumu Stremljenja i novine u medicini, Medicinski fakultet u Beogradu, 7.12.2016. godine.

Rad je podržan od strane Ministarstva za nauku i tehnološki razvoj Republike Srbije ugovorom broj 175095.

\section{NAPOMENA}

\section{Literatura}

1. Dikensoy O, Misra H, Ekinci E, Light RW. Tracheobronchial aspiration. U: Nava S, Welte T. Respiratory Emergencies. ERS Monograph 2006; 11 (36):108-124.

2. Fitzpatrick PC, Guarisco JL. Pediatric airway foreign bodies.J La State Med Soc. 1998;150(4):138-141.

3. Dhadke SV, Chaudhari AL, Deshpande NS, Dhadke VN, Sangle SA. Foreign Body in Left Main Bronchus. J Assoc Physicians India. 2015;63(7):70-71.

4. Gupta SL, Swaminathan S, Ramya R, Parida S. Fractured tracheostomy tube presenting as a foreign body in a paediatric patient. BMJ Case Rep. 2016 Mar 8;2016. pii: bcr2015213963.

5. Feltbower S, McCormack J, Theilen U. Fatal and near-fatal grape aspiration in children.Pediatr Emerg Care. 2015;31(6):422-4.

6. De Wilde BA, Malfait TL, Bonte K, Malfait TL. Dental prosthesis aspiration: An uncommon cause of respiratory distress. Acta Clin Belg. 2016 May 3:1-4. [Epub ahead of print]

7. Behera C, Prasad H, Mridha AR, Swain R. Fatal chilli bite. Med Leg J. 2016 Mar 11. pii: 0025817216638995. [Epub ahead of print]

8. Kupali E, Khemasuwan D, Lee P, Mehta AC. Pills and air passage. Chest 2013;144:651-60.

9. Mehta AC, et al. A foreign body of a different kind: Pill aspiration. Ann Thorac Med. 2014; 9(1): 1-2.

10. Elhasani NB. Tracheobronchial foreign bodies in the Middle East. A Baghdad study. J Thorac Cardiovasc Surg. 1988;96(4):621-5.

11. Burton EM, Brick WG, Hall JD, Riggs W Jr, Houston CS. Tracheobronchial foreign body aspiration in children. South Med J. 1996 Feb;89(2):195-198.

12. Mahafza T, Khader Y. Aspirated tracheobronchial foreign bodies: a Jordanian experience. Ear Nose Throat J. 2007; 86(2):107-110.

13. Brkić F, UmihanićS.Tracheobronchialforeignbodiesinchildren. Experienceat ORL clinicTuzla, 1954-2004.Int J PediatrOtorhinolaryngol. 2007;71(6):909-15.

14. Ali SR, Mehta AC. Alive in the Airways: Live Endobronchial Foreign Bodies.Chest. 2017 Feb;151(2):481-491.

15. Chandra TJ, Dash S, Srinivas G, Rao PV. Hepatopleuropulmonary amoebiasis-a case report.J Indian Med Assoc. 2013;111(5):348.

16. Taylor JK, Fleming GB, Singanayagam A, Hill AT, Chalmers JD. Risk factors for aspiration in community-acquired pneumonia: analysis of a hospitalized UK cohort. Am J Med. 2013;126(11):995-1001.

17. Wong SC, Tariq SM. Cardiac arrest following foreign-body aspiration. Respir Care. 2011;56(4):527-529.

18. Sinha V, Chhaya V, Barot DS, Mehta K, Patel P, Patil S, et al. Foreign body in tracheobronchial tree. Indian J Otolaryngol Head Neck Surg. 2010;62(2):168-170.

19. Mehta A, Gupta A, Aziz Ks A, Venkitakrishnan r. Endobronchial Foreign Body (FB): A Rare Cause of Empyema. J ClinDiag Res 2015;-9(4):OJ02-OJ03

20. Lanspa MJ, Peyrani P, Wiemken T, Wilson E, Ramirez JA, Dean NC. Characteristics associated with clinician diagnosis of aspiration pneumonia: A descriptive study of afflicted patients and their outcomes. $J$ Hosp Med 2015; 10 (2):90-96.

21. DiBardino D, Wunderink R. Aspiration pneumonia: A review of modern trends.J Crit Care 2014;30(1): 40-48.

22. Brander PE, Taskinen E, Stenius-Aarniala B. Fire eater's lung. Eur Respir J 1992; 5: 112-114.
23. Katsumi H, Tominaga M, Tajiri M, Shimizu S, Sakazaki Y, Kinoshita $\mathrm{T}$, et al. A case of lipoid pneumonia caused by inhalation of vaporized paraffin from burning candles. Respir Med Case Rep. 2016 Oct 5;19:166-168.

24. Osman GA, Ricci A, Terzo F, Falasca C, Giovagnoli MR, Bruno P, et al. Exogenous lipoid pneumonia induced by nasal decongestant. Clin Respir J. 2016 Sep 22. doi: 10.1111/crj.12557. [Epub ahead of print]

25. Zissin R, Shapiro-Feinberg M, Rozenman J, et al. CT findings of the chest in adults with aspirated foreign bodies. Eur Radiol.2001;11:606-611.

26. Edmond KM, Attia JR, Deste CA, Condon JT. Drowning and near-drowning in Northern Territory children. Med J Aust. 2001;175(11-12):605-608.

27. Zhu Y, Xu G, Li H, Huang Y, Ding K, Chen J. Epidemiology and risk factors for nonfatal drowning in the migrant children. Southeast Asian J Trop Med Public Health. 2015;46(6):1112-23.

28. Byard RW. Drowning and near drowning in rivers. Forensic Sci Med Pathol. 2017 Mar 9. doi: 10.1007/s12024-017-9858-5. [Epub ahead of print] No abstract available.

29. Corrigan D, Paton JY. Paediatric emergencies. In: Nava S, Welte T. Respiratory Emergencies. ERS Monograph 2006; 11 (36): 214-240.

30. Pugmire BS, Lim R, Avery LL. Review of Ingested and Aspirated Foreign Bodies in Children and Their Clinical Significance for Radiologists.Radiographics. 2015;35(5):1528-1538.

31. Baqais KA, Mahoney M, Tobler K, Hui A, Noseworthy M. Pediatric sand aspiration managed using bronchoscopy and extracorporeal membrane oxygenation. Can Respir J. 2015 Sep-Oct;22(5):261-2.

32. Metcalf KB, Michaels AJ, Edlich RF, Long WB. Extracorporeal membrane oxygenation can provide cardiopulmonary support during bronchoscopic clearance of airways after sand aspiration. J Emerg Med. 2013 Sep;45(3):380-3. doi: 10.1016/j.jemermed.2013.03.017.

33. Chochinov AH, Baydock BM, Bristow GK, Giesbrecht GG. Recovery of a 62 -year-old man from prolonged cold water submersion. Ann Emerg Med. 1998;31(1):127-131.

34. Dong YC, Zhou GW, Bai C, Huang HD, Sun QY, Huang Y, et al. Removal of tracheobronchial foreign bodies in adults using a flexible bronchoscope:experience with 200 cases in China. Intern Med. 2012;51: 2515-2519.

35. Sriratanaviriyakul N, Lam F, Morrissey BM, Stollenwerk N, Schivo M, Yoneda KY. Safety and Clinical Utility of Flexible Bronchoscopic Cryoextraction in Patients With Non-neoplasm Tracheobronchial Obstruction: A Retrospective Chart Review. J Bronchology Interv Pulmonol. 2015; 22(4):288-293.

36. Fruchter O, Kramer MR. Retrieval of various aspirated foreign bodies by flexible cryoprobe: in vitro feasibility study. Clin Respir J. 2015;9(2):176-179.

37. Tenda ED, Yakub A, Pitoyo CW, Fardizza F. Combination of bronchoscopic cryoextraction and argon plasma coagulation in treatment of total central airway obstruction caused by giant blood clot formation in massive airway bleeding. Respir Med Case Rep. 2016 Jun 13;19:9-11. doi: 10.1016/j.rmcr.2016.06.002. eCollection 2016.

38. Lei J, Zhao J, Tian F, Wang X, Zhou Y, Li X, Wang J. Clinical analysis of eight patients with blunt main stem bronchial injuries. J Thorac Dis. 2017 Jan;9(1):194-199.

39. Rubio E, Gupta P, Ie S, Boyd M. Cryoextraction: A novel approach to remove aspirated chewing gum. Ann Thorac Med. 2013;8(1):58-59. 